Ethiopian Journal of Environmental Studies \& Management 8(1): 69 - 80, 2015.

ISSN:1998-0507

doi: http://dx.doi.org/10.4314/ejesm.v8i1.7

Submitted: October 31, 2014

Accepted: January I5, 2015

\title{
SPATIAL MODELLING OF POPULATION AT RISK AND PM 2.5 EXPOSURE INDEX: A CASE STUDY OF NIGERIA
}

\author{
*LAWAL, 0.1 AND ASIMIEA, A.0. ${ }^{2}$ \\ ${ }^{1}$ Department of Geography and Environmental Management, Faculty of Social Sciences, \\ University of Port Harcourt, P.M.B 4323, Choba Campus, Port Harcourt. \\ ${ }^{2}$ Department of Crop and Soil Science, Faculty of Agriculture, University of Port Harcourt,
}

\begin{abstract}
Particulate matter is a primary air pollutant, widely reported as important for public health especially for respiratory problems. However, monitoring, spatial representation and development of associated risk indicators have been major problems undermining formulation of relevant policy on air quality. This study used remotely sensed PM data complemented with population data to quantify population at risk and develop an Exposure Index (EI). Population at risk was computed from the population density data using the percentage contribution of two different ages groups (ages of 0-19 and 65+) and intersecting this with the PM concentration classes. El is the sum product of the air quality measure and the population of vulnerable group per unit area. Almost the entire study area has $P M_{2.5}$ concentration above the WHO guideline. Change in $\mathrm{PM}_{2.5}$ concentration showed that, around $54 \%$ of the study area remains the same, $43 \%$ improved and the remaining areas showed reduction. Between 77 million and 81million of young vulnerable people were at risk over the period and about 4 million elders were at risk. El ranges between $1.5 \times 10^{-4}$ and $8.3 \times 10^{-2}$ per capita in 2001 and $1.9 \times 10^{-4}$ and $1.5 \times 10^{-1}$ per capita in 2010. This situation presents an environmental health burden in relation to potential risk of continuous exposure to dangerous levels of $P M_{2.5}$. This information is necessary for rapid assessment of environmental health risk. However, research on the computation and exploration of other risk measures such as relative and attributable risks would further enhance policy making in relation to environmental health.
\end{abstract}

Key Words: Population at risk, $P M_{2.5}$; Spatial modeling, GIS, Exposure index, environmental health

\section{Introduction}

There has been a clear and relevant effort by researchers across the world to quantify the impact of poor air quality on human health, thereby informing better policy on management of air pollution and public health. Particulate matter (PM) is a primary air pollutant and includes all solids and/or liquids (dust and mists) suspended in the atmosphere and may or may not be visible as soil particles, soot, lead, lead and so on. Most of the PM will eventually settle out of the atmosphere, but microscopic particle may remain in the atmosphere for weeks or years (Berg and Hager, 2009). The microscopic particles served as binding

*Corresponding Author: Lawal, O.

Email: olalaw@hotmail.com 
surfaces for various other chemicals which are inhaled and caused various respiratory diseases as they are inhaled into the lungs (Berg and Hager, 2009). Among PM, those with aerodynamic diameter less than $10 \mu \mathrm{m}$ $\left(\mathrm{PM}_{10}\right)$ and $2.5\left(\mathrm{PM}_{2.5}\right)$ are widely reported as important for public health.

The effect of PM on human health has been reported to include acute pulmonary problems and cardiovascular problems which may consequently result in hospitalisation and premature death (Bhattacharjee et al., 1999). Other adverse effects reported include changes in pulmonary function, changes in host defence mechanisms, cancer, chronic respiratory problems, low birth weight and infant mortality (Bhattacharjee et al., 1999). Air pollution in urban areas is especially of special interest because of persistent high PM concentration, exposure of large population and the possibility of delayed health effects (Romieu et al., 2012). However, the biological mechanism linking PM exposure to mortality and morbidity are still not clear (Marcazzan et al., 2001), but there are evidences that socioeconomic condition, age, concentration and duration of exposure, type and characteristic of PM, season influence the effect of PM human health (Le et al., 2012). However, studies have shown that indoor $\mathrm{PM}_{2.5}$ concentration is more representative of ambient $\mathrm{PM}_{2.5}$ and this is responsible for a higher proportion of PM-related morbidity and mortality (Bhattacharjee et al., 1999).

In Nigeria, for example, the situation of poor air quality is further exacerbated by the number of motorbike rider (Okada), lack of enforcement of road worthiness of vehicles (toxic exhaust emissions), lack of enforcement of land use zoning (location of industrial activities in populated areas) and lack of/ inefficiencies of other regulatory framework that could reduce the PM generation. Furthermore, with problems of cost, variation in monitoring equipment, and issue of spatial coverage, GIS and remote sensing technologies present veritable option in alleviating such problems.

There are myriads of models and simulations used in understanding environment, urban sprawl, waste management, landuse change etc. (Lawal, 2009, 2014). However, model and indicators are different. Models aim to predict the actual impact while indicators aim to provide information on risk or potential effect. Air pollution in relation to ambient or outdoor air quality is a major environmental risk to human health. Across many developing countries, outdoor air quality monitor is often sparse and where they exist, usually represent the condition for the immediate environment (Gutierrez, 2010). This constitutes a major data gap which hampers planning and proper policy making. Remote sensing offers a potential for filling this data gap in the air quality dataset due to its coverage in time and space. Recent advances in remote sensing have shown high correlation between satellite data and ground level $\mathrm{PM}_{2.5}$ concentration e.g. Tsai et al., (2011). From these efforts various models have been developed and tested to quantify and fill the missing gaps in the air quality dataset.

According to WHO (2014), policies reducing air pollution by any nation could significantly reduce burden of diseases such as stroke, heart disease, lung cancer and chronic and acute respiratory diseases. They also reported that PM component of air pollution being closely related to lung cancer. Moreover, they estimated ambient air pollution caused 3.7 million premature deaths in cities and rural areas and could be attributed to exposure to PM. A 
disproportionately high percentage $(88 \%)$ of these deaths was found to occur in the low- and middle income countries. These burden estimates show that there is a need for concerted effort at the regional, national and international levels since it is obvious that the control of outdoor air pollution is beyond individuals due to huge impact reported. Therefore, it is necessary to create an indicator which could identify, quantify and located vulnerable population, as well as their level of exposure. This thus will provide relevant information for jumpstarting policy making to mitigate problems associated with ambient air quality and its attendant effects.

Therefore, this study aims to develop risk index, which combines total number of vulnerable people and air quality value for a particular area. This will serve as a tool to express the risk of the negative effect (as enumerated in the introduction) of low air quality. The study also aims to provide an estimate of population of vulnerable people at risk to different concentration of $\mathrm{PM}_{2.5}$, thus we will highlight the spatial distribution of ambient air quality in Nigeria and quantify the average exposure of vulnerable group to prevailing ambient air quality.

\section{Methodology}

\section{Data Collection and Modelling}

$\mathrm{PM}_{2.5}$ annual mean data for 2001 and 2010 were used for the study. The data have global coverage (Battelle Memorial and Center for International Earth Science Information Network, 2013). The data set represents latest advances in the field of remote sensing and environmental modelling. Data for Nigeria was extracted from this dataset.

In order to model population at risk and create an index of exposure to particulate matter, data were sourced for population.
Population density data were sourced for 2000 and 2010. The 2000 was sourced from GRUMP v1 (Balk et al., 2006; Center for International Earth Science Information Network, International Food Policy Research Institute, The World, and Centro Internacional de Agricultura Tropical, 2011) . In representing the 2010 population density, the UN Population division estimate was used (Population Division, 2010), method and input data used in generating the grid map were described by Linard et al. (2012). In addition to the population density, the age structure data were also sourced in order to evaluate the population of the vulnerable groups. Age structure data were sourced from World Population Prospect dataset (UN, 2013). Data for the age structure for 2000 and 2010 for Nigeria were extracted for the medium variant and total population per age group was used to calculate percentage of each of the identified vulnerable groups. The vulnerable groups in the study were defined as age groups $0-19$ years and 65 years old and above. In order to compute the proportion of these across the country, the total population of these was summed and percentage was calculated based on the total population from the database (World Population Prospect: The 2012 Revision). Computed proportions were then multiplied by the population density grid within ArcGIS (ESRI, 2011) to create a grid of vulnerable population (i.e. same resolution as that of the population density grid map). From this, four grid maps were created two for each year (one for each vulnerable group).

Modelling operations were carried out in two phases: data processing and overlay analysis. $\mathrm{PM}_{2.5}$ data and population related dataset were pre-processed to prepare them for the overlay analysis. All operations 
were carried out within ArcGIS (ESRI, 2011).

Population data were geo-processed to create a map of vulnerable population across the country. This was done by using the percentage distribution of each of the vulnerable groups to derive a representation of vulnerable group per unit area across the study area. Derived distribution was then aggregated to the second administrative boundaries (Local Government AreaLGA), this gave an overview of the number of the identified vulnerable groups within this geographical unit.

The pre-processing operation was also carried out for the PM data, this grid data was re-sampled using the bilinear interpolation method. This method usually results in smoothing of the data, but it is adequate for continuous data and will not generate data outside the range of the input values. Interpolation was carried out to match the resolution of the PM data with that of the population data. Re-sampled dataset was then classified according to their difference to the WHO guideline.

EI was prepared as the sum product of the air quality measure and the population of vulnerable group per unit area. The resulting map is a population weighted PM EI. Thus, places with high PM values and high population of vulnerable group results in higher EI values. This was done to prevent administratively tied index from having high index value for large administrative unit when they are actually less populated than smaller administrative units with larger population. The index was then summed using zonal statistics tools within ArcGIS to calculate the total value of the index at the LGA level. This value represents the average concentration exposed to by the population of each LGA.

In modelling the population at risk an overlay analysis was carried out, using the intersection of the population data and the PM concentration class data. Concentration class data were converted to endemic zone/area map by converting the classes to polygons. The polygon served as input in the computation of the population at risk for each of the classes derived.

\section{Results and Discussion Spatial Distribution of $\mathbf{P M}_{2.5}$}

$\mathrm{PM}_{2.5}$ derived from remotely sensed data shows a spatially explicit distribution of ambient PM across the study area (Figure 1). Four classes were derived (Table 1) to aid visualisation of the dataset. For Class 1 ambient PM concentration, about $0.3 \%$ and $16.5 \%$ of the area falls within this class for 2001 and 2010 respectively. In 2010 about $65 \%$ of the total land mass falls within Class 2 compared to about $36 \%$ in 2001. However, Class 3 recorded a reduction from 2001 to 2010 of about 28\%. Class 4 also recorded a reduction of about $18 \%$ from 2001 to 2010.

The spatial distribution of the class showed that almost the entire study area has $\mathrm{PM}_{2.5}$ concentration above the WHO guideline of $10 \mu \mathrm{g} / \mathrm{m}^{3}$ across the two periods under consideration. This is in line with the observations of Efe (2008), the author examined the spatial distribution of particulate air pollution in Nigeria cities and reported that $70 \%$ of the cities studies have values above the daily and annual mean recommended by WHO. Works of Ezeh et al. (2012) and Obioh et al. (2013) also corroborate the levels of $\mathrm{PM}_{2.5}$ observed from the dataset used for this study. There are serious implications for human health with this level of ambient air quality, especially since $\mathrm{PM}_{2.5}$ has been implicated in many pulmonary and cardiovascular 
Ethiopian Journal of Environmental Studies and Management Vol. 8 no. 12015
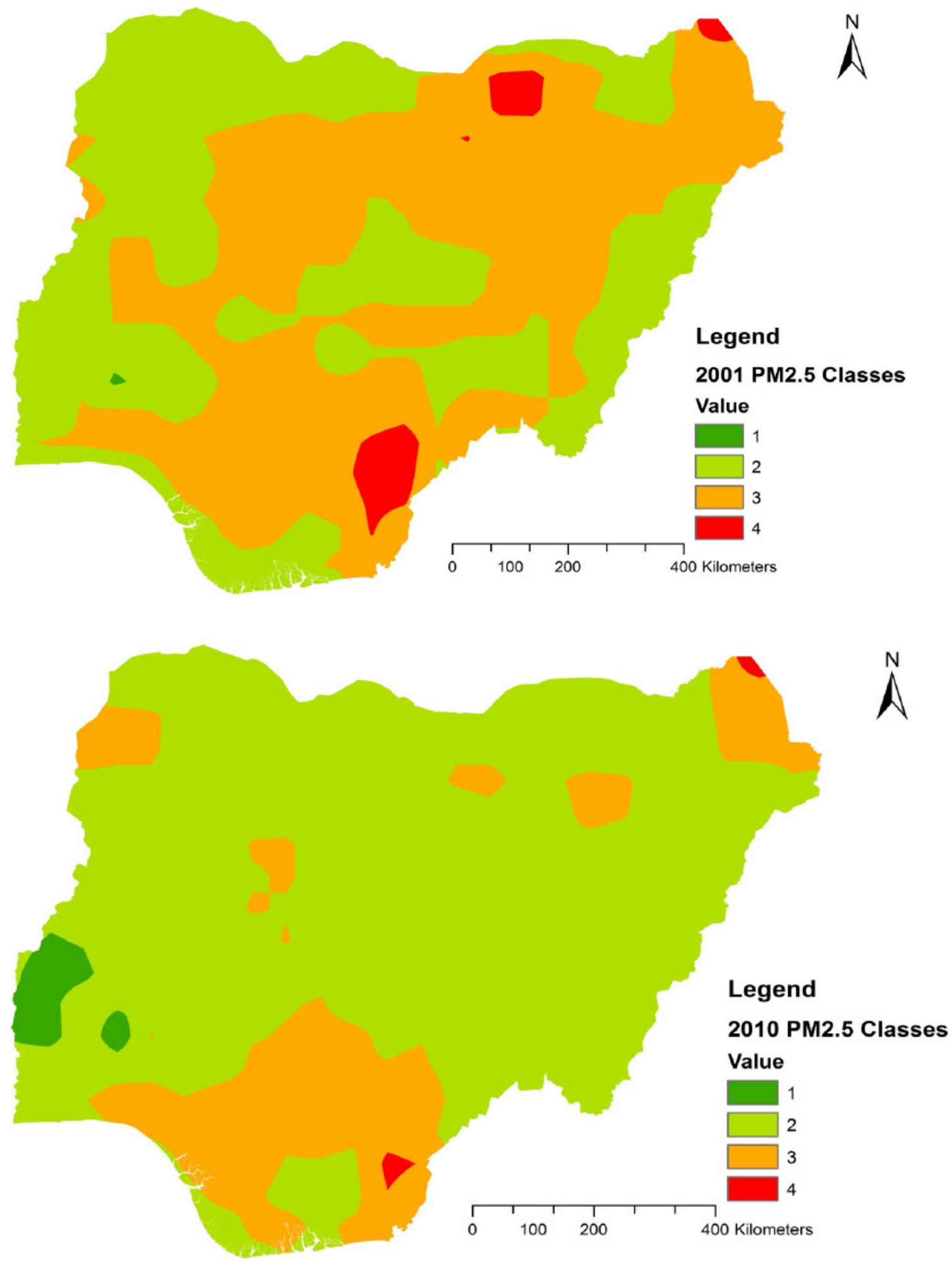

Figure 1: Spatial distribution of PM2.5 concentration in 2001(a) and 2010(b) 
Exploration of Population at Risk to PM 2.5

Intersecting human population of defined vulnerable groups with four classes of $\mathrm{PM}_{2.5}$ classification presented an overview of the total population of people exposed to different range of PM concentration. Results indicate that over the period of observation there were considerably increase in the population of the two vulnerable groups living within the WHO guideline of $10 \mu \mathrm{g} / \mathrm{m}^{3}$. The number of young people living within the WHO guideline increased from about 35, 000 to about 1.1 million in 2010, similarly there was an increase of over 57,000 individuals of 65 years of age and above living in areas within or below the guideline figure. These population figures further highlight how low and middle income countries disproportionally suffers the burden of outdoor air pollution (WHO, 2014)

Table 1: Population at Risk to different concentration of $\mathrm{PM}_{2.5}$

\begin{tabular}{|c|c|c|c|c|c|c|c|}
\hline \multirow[t]{3}{*}{ Class } & \multirow{3}{*}{$\begin{array}{l}\mathrm{PM}_{2.5} \\
\left(\mu \mathrm{g} / \mathrm{m}^{3}\right)\end{array}$} & \multicolumn{4}{|c|}{ Population at Risk } & \multicolumn{2}{|c|}{ Change } \\
\hline & & \multicolumn{2}{|c|}{ 0-19 Years of Age } & \multicolumn{2}{|c|}{ Above 65 Years of Age } & 0-19 Yrs. & Above 65 \\
\hline & & 2000 & 2010 & 2000 & 2010 & 200 & -2010 \\
\hline 1 & $\leq 10$ & 34,922 & $1,170,570$ & 1,798 & 58,862 & $1,135,647$ & 57,063 \\
\hline 2 & $10.001-20$ & $35,360,100$ & $60,423,200$ & $1,820,940$ & $3,038,360$ & $25,063,100$ & $1,217,420$ \\
\hline 3 & $20.001-30$ & $39,380,700$ & $20,192,600$ & $2,027,990$ & $1,015,380$ & $(19,188,100)$ & $(1,012,610)$ \\
\hline 4 & $>30$ & $1,893,190$ & 72,533 & 97,493 & 3,647 & $(1,820,656)$ & $(93,845)$ \\
\hline
\end{tabular}

NB. Value in bracket indicate negative numbers

In areas with $\mathrm{PM}_{2.5}$ above the guideline and double the guideline figures, there was an increase across the country for both vulnerable groups examined. For younger individuals, there was an increase of about 25 million over the period examined while for the elders the increase was considerably higher (1.2 million). For the other two classes of concentration there were decreases of about 19.2 million and 1.8 million for younger individuals and about 1 million and 94,000 for these classes of $\mathrm{PM}_{2.5}$ concentration for the elderly. 


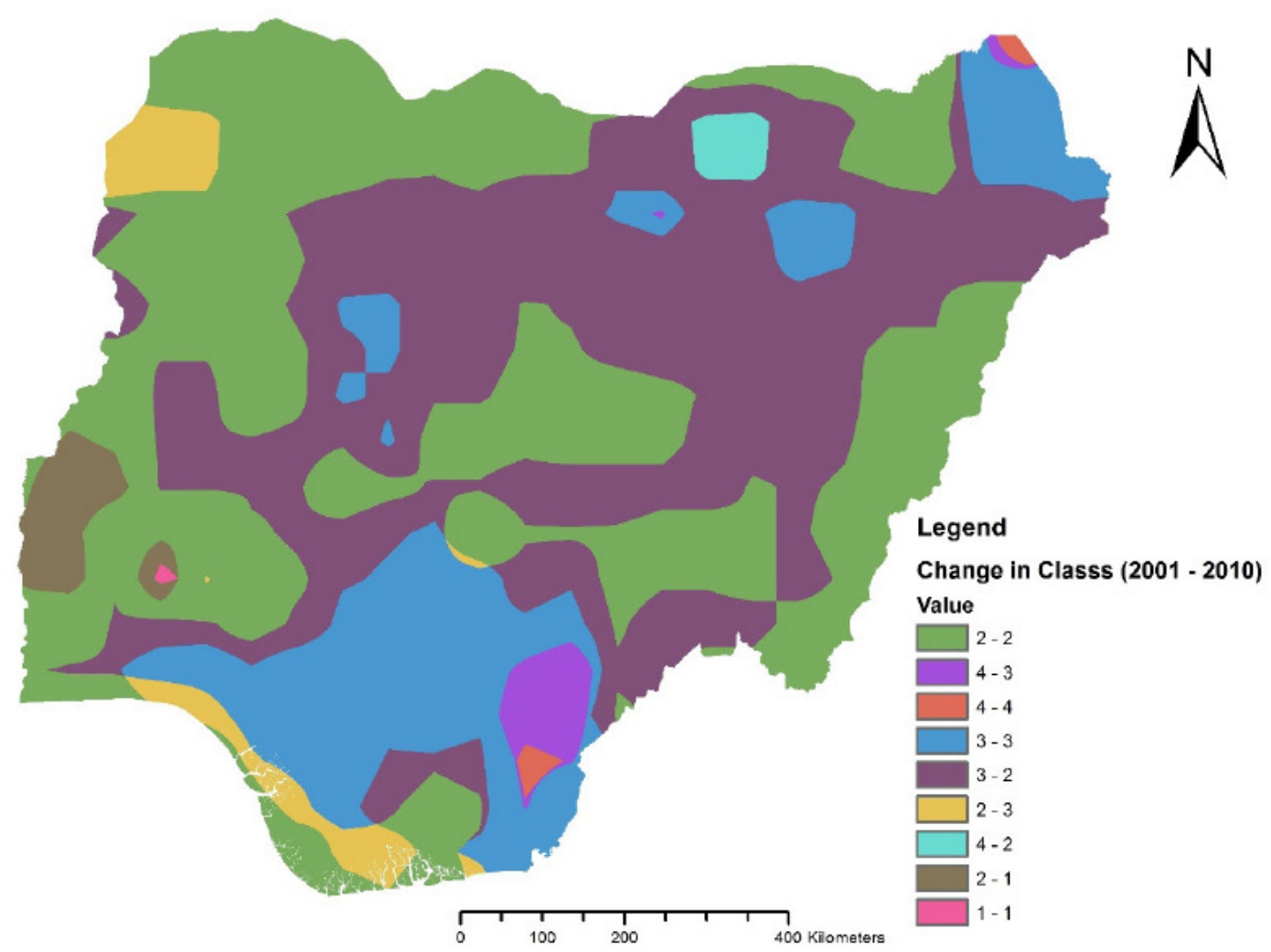

Figure 2: Change in class of $\mathrm{PM}_{2.5}$ concentration from 2001 to 2010

Examination of the change in $\mathrm{PM}_{2.5}$ concentration over the period, about $54 \%$ of the study area remains in the same class as they were in 2001 . However about $43 \%$ showed an improvement (i.e. decrease in mean annual $\mathrm{PM}_{2.5}$ concentration) while the remaining areas witnessed a degradation in ambient air quality over the period under study.

From the foregoing, one could deduce that there were positives in relation to the increase in numbers of people within the guideline and decrease in the number living at the extremes of $\mathrm{PM}_{2.5}$ concentration. This could be attributed to the improvement in ambient air quality (Figure 1) over the period considered (reduction from Class 4 to 3,3 to 2,4 to 2 and 2 to 1 ). Moreso, there is an increase in population density (World Bank Estimates) for the country (from about 136 individuals $/ \mathrm{km}^{2}$ to 176 individuals $/ \mathrm{km}^{2}$ ), this could also explain why there are more people in these areas of better air quality. However, this increasing population density also explains why there are more people, especially the young, vulnerable groups (making up more than half of the population) are increasingly exposed to very high level of $\mathrm{PM}_{2.5}$. While the number decrease for the extreme classes (3 and 4) for both groups of vulnerable individuals, the increase over the years present a difficult challenge which could overwhelm the health facilities and frameworks in place in the country due to the attendant chronic effect of this level of exposure. This low level of air quality coupled with high population density is an additional national burden.

\section{Spatial Representation of EI}

EI aggregated to the LGA boundary shows the average exposure per person 
within the smallest geographical unit in the country. In 2001, there is a swath of high index value across the North Central to the North Eastern part of the country as well as from the South-East towards the South-
South regions of the country (Figure 2a). There is a cluster of high values which could be related to the location of Lagos Metropolis and some parts of Ogun State with high EI for the same year.

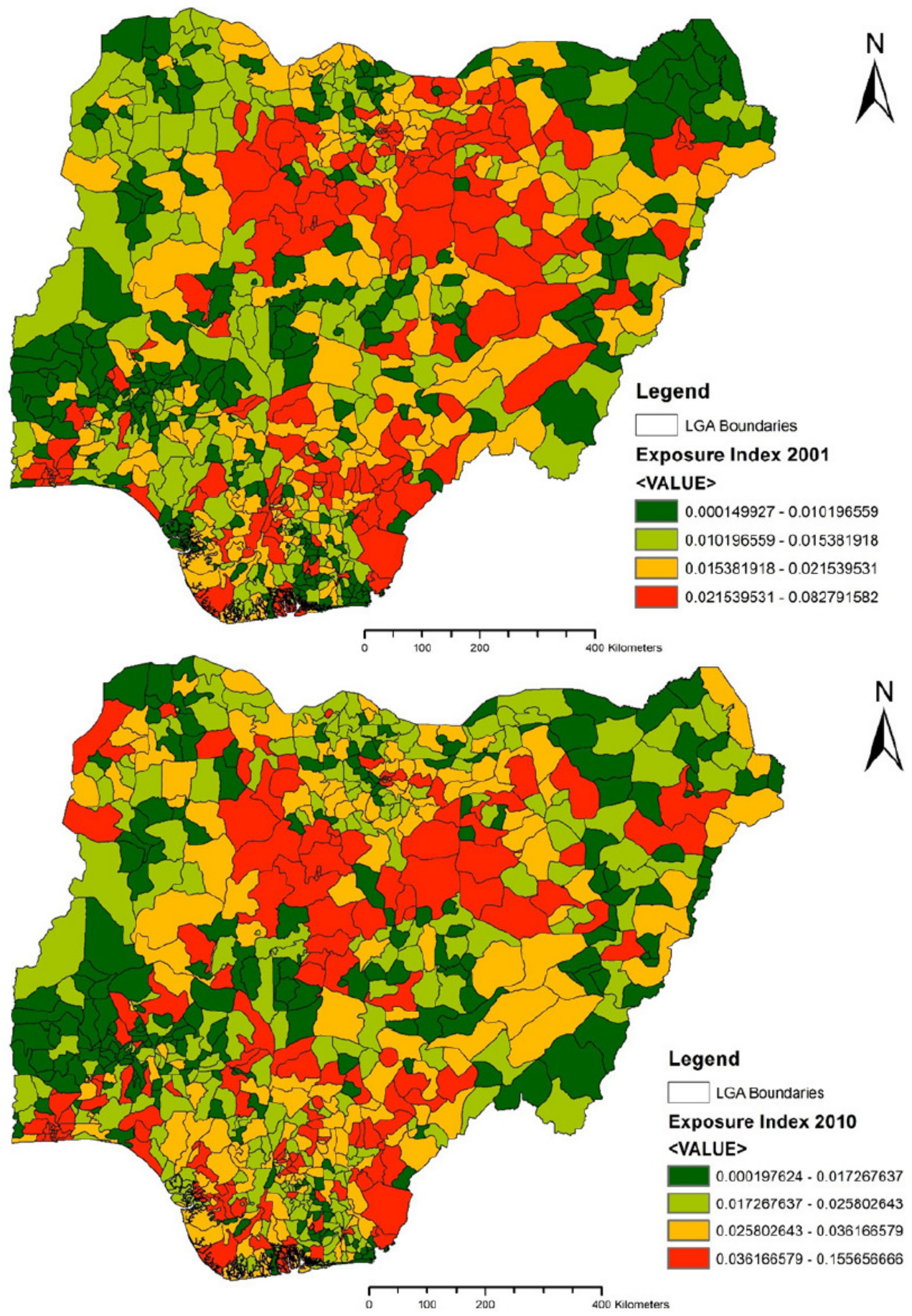

Figure 3: Spatial distribution of EI for 2001(a) and 2010(b) 
Dotted around the Niger Delta are pockets of areas with high EI and a number of low exposure areas. But generally, the North Central and South Eastern area down to the South-South has the highest concentration of high exposure areas. In 2010, the pattern is similar to these high regions still persists (Figure 2b). In addition, outside this core area (i.e. North Central, South East and South South) most LGA witness an improvement in their EI and few were showing deterioration.

The results indicate areas with varying levels of EI. High exposure could be attributed to a combination of low air quality and high population density. With this, it is possible to possible to deduce at the local level where vulnerable people intersect with areas of low air quality. The index values show that many of the urban conglomerations have high exposure, which signifies that there is a high per capita exposure to $\mathrm{PM}_{2.5}$. Moreover, areas with sparse population have a relatively low EI value. Across the study area, large expanse of populated area shows considerably high EI, this situation is common in the Niger Delta region, some parts of the South Western region as well as major urban centres of the North East and North West of the country.

Furthermore, a query of the differences between the two years reveals areas where there are increases in EI. Figure 3 was generated using the spatial query to find areas with EI less than 0 thus areas designated as 1 are true and 0 as false. The result shows that a significant proportion of the area understudied recorded no increase in EI (94\%) which is a positive development.

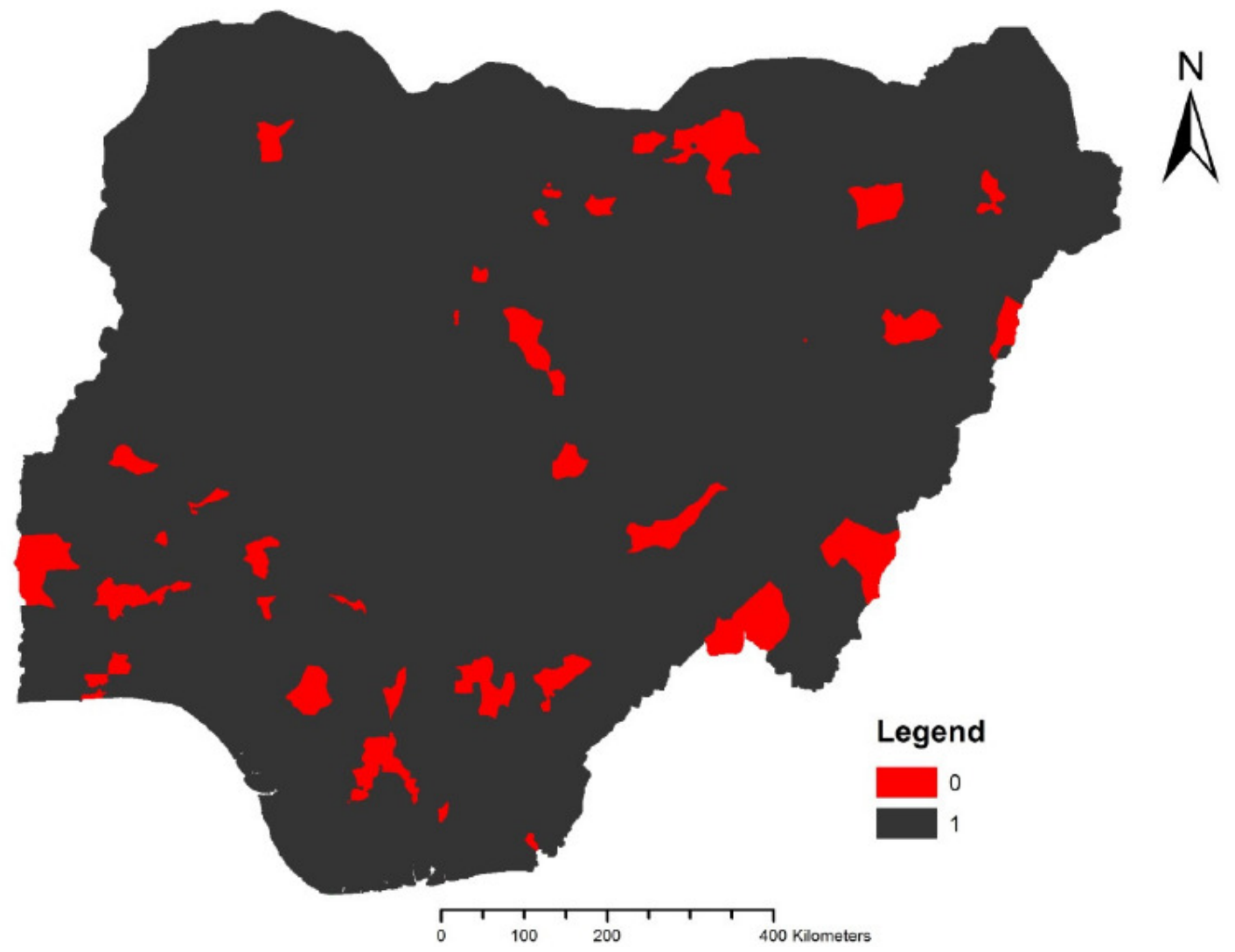

Figure 4: Spatial query results of area with increase in EI 
A total of about $53,000 \mathrm{~km}^{2}$ of the study area recorded an increase in EI, most of this increase occurred in and around populated places across the country. The increase could be attributed to increase in population generally across the country. Moreover, increases in EI could also be as a result of the increase in PM created by human activities as brought about by the increasing population.

This result highlights the importance of monitoring and the need to improve urban area's air quality. Rural areas should also not be neglected, but urban areas need to take precedence due to the higher risk to a large number of people. Results across Europe (WHO, 2014) showed an average reduction in life expectancy of 8.6 months in relation to exposure to PM. Moreover, in 2013 the WHO's International Agency for Research on Cancer, in a press release announce the classification of outdoor air pollution (OAP) and PM as carcinogenic to humans (Group 1) and also noted a positive association between OAP and increased bladder cancer after review of scientific literature. With this understanding there is a need to develop policies which are geared towards reducing the exposure and improving air quality across urban areas. These will consequently reduce environmental health burden and contribute to sustainable development.

\section{Conclusion}

The study presents a method which could be used for regional or national planning for environmental and health policy decision making. To achieve this, the study highlights the spatial distribution of vulnerable people using aggregated data at the LGA levels and intersected this spatial distribution with the mean annual concentration of $\mathrm{PM}_{2.5}$ across the country for 2001 and 2010. This combined dataset was then used to compute the population at risk for different ranges of $\mathrm{PM}_{2.5}$ concentration. Furthermore, a population weighted EI was used to evaluate the per capita PM exposure at the local scale.

The results show that across the country very few places have annual mean values of $\mathrm{PM}_{2.5}$ below the WHO guideline value and large numbers of vulnerable people are exposed to these dangerous levels of air quality. Guideline values are meant to provide targets and thus promote movement towards a lower PM concentration. With this in mind, looking at the values obtain across the country, presents a worrying situation. It creates a significant burden on the national health infrastructure and portends great risks to human and sustainable development. Further to this is the increase in EI across many of the urban centre, thus increasing the risk of attendant health effect (chronic and acute) of low air quality to a large number of people. Thus, prevalent use of Kerosene stove and other activities contributing to increases in PM concentration both indoor and outdoor, we could deduce that reduction in life expectancy could be higher across our study area in comparison to figures obtained in Europe where air quality are well within WHO guideline values.

Across the study area a huge number of vulnerable people are found in high risk regions (low air quality areas). While this information is necessary for rapid assessment of environmental health risk, it is also important the effort be made to explore indoor air quality as well as the interaction of other socio-economic, demographic and physiographic attributes on development of pulmonary and 
cardiovascular problems. Research on the computation and exploration of other risk measures such as relative and attributable risks would further enhance policy making in relation to environmental health.

\section{References}

Alex de, S., Marc, A.L., Erica, Z., Stephanie, W. and Malanding, J. (2014). Using satellite data to develop environmental indicators. Environmental Research Letters, 9(8), 084013.

Balk, D.L., Deichmann, U., Yetman, G., Pozzi, F., Hay, S.I., and Nelson, A. (2006). Determining Global Population Distribution: Methods, Applications and Data. Advances in Parasitology, 62: 119-156.

Battelle Memorial, I., and Center for International Earth Science Information Network, C.C.U. (2013). Global Annual Average PM2.5 Grids from MODIS and MISR Aerosol Optical Depth (AOD). Retrieved from: http://dx.doi.org/10.7927/H4H41PB4

Berg, L.R., and Hager, M.C. (2009). Air and Air Pollution Visualizing Environmental Science (Vol. Visualizing, pp. 196). New York: Wiley.

Bhattacharjee, H., Drescher, M., Good, T., Hartley, Z., Leza, J., Lin, B., Moss, J., Massey, R., Nishino, T., Ryder, S., Sachs, N., Tozan, Y., Taylor, C. and Wu, D. (1999). Particulate Matter in New Jersey. In D. Kammen, T. Holloway \& D. Murillo (Eds.), WWS 589: Methods in Science, Technology, and Public Policy. New Jersey: Woodrow Wilson School of
Public and International Affairs, Princeton University.

Center for International Earth Science Information Network, International Food Policy Research Institute, The World Bank, \& Centro Internacional de Agricultura Tropical. (2011). Global Rural-Urban Mapping Project, Version 1 (GRUMPv1): Population Density Grid. Retrieved from: http://dx.doi.org/10.7927/H4R20Z93

Efe, S.I (2008). Spatial distribution of particulate air pollution in Nigerian cities: implication for human health. Journal of Environmental Health Research, 7(2): 107-116.

Ezeh, G.C., Obioh, I.B., Asubiojo, O.I. and Abiye, O.E. (2012). PIXE characterization of PM10 and PM2. 5 particulates sizes collected in Ikoyi Lagos, Nigeria. Toxicological \& Environmental Chemistry, 94(5): 884-894.

ESRI. (2011). ArcGIS Desktop (Version 10). redlands, CA: Enviromental Systems Research Institute.

Gutierrez, E. (2010). Using satellite imagery to measure the relationship between air quality and infant mortality: an empirical study for Mexico. Population and Environment, 31(4), 203-222. doi: 10.1007/s11111-009-0096-y

Lawal, O. (2009). Analysis of land use changes in the Thames Gateway: the change-pattern approach. (PhD), University of East London, London.

Lawal, O. (2014). Wasteful disposition: Analysis of municipal household waste using geodemographic classification. Waste Management \& Research, 32(2): 170-174. doi: 10.1177/0734242x13519692 
Le, T.G., Ngo, L., Mehta, S., Do, V.D., Thach, T.Q., Vu, X.D., Nguyen, D.T., and Cohen, A. (2012). Effects of short-term exposure to air pollution on hospital admissions of young children for acute lower respiratory infections in Ho Chi Minh City, Vietnam. Res Rep Health Eff Inst (169): 5-72; discussion 73-83.

Linard, C., Gilbert, M., Snow, R.W., Noor, A.M. and Tatem, A.J. (2012). Population Distribution, Settlement Patterns and Accessibility across Africa in 2010. PLoS ONE, 7(2), e31743. doi:

10.1371/journal.pone.0031743

Marcazzan, G.M., Vaccaro, S., Valli, G. and Vecchi, R. (2001). Characterisation of $\mathrm{PM}_{10}$ and $\mathrm{PM}_{2.5}$ particulate matter in the ambient air of Milan (Italy). Atmospheric Environment, 35(27): 4639-4650. doi: http://dx.doi.org/10.1016/S13522310(01)00124-8

Obioh, I.B., Ezeh, G.C., Abiye, O.E., Alpha, A., Ojo, E.O. and Ganiyu, A. K. (2013). Atmospheric particulate matter in Nigerian megacities. Toxicological \& Environmental Chemistry, 95(3): 379-385. doi: 10.1080/02772248.2013.790970

Population Division, UN. (2010). Alpha version 2010 and 2014 estimates of numbers of people per grid square, with national totals adjusted to match UN population division estimates. Retrieved from: http://esa.un.org/wpp/

Romieu, I., Gouveia, N., Cifuentes, L.A., de Leon, A.P., Junger, W., Vera, J. and Tzintzun-Cervantes, G. (2012). Multicity study of air pollution and mortality in Latin America (the ESCALA study). Res. Rep. Health Eff. Inst. (171): 5-86.

Tsai, T.-C., Jeng, Y.-J., Chu, D. A., Chen, J.-P. and Chang, S.-C. (2011). Analysis of the relationship between MODIS aerosol optical depth and particulate matter from 2006 to 2008. Atmospheric Environment, 45(27), 4777-4788. doi: http://dx.doi.org/10.1016/j.atmosenv. 2009.10.006

UN, Department of Economic and Social Affiars, Population Division. (2013). World Population Prospects: The 2012 Revision, Key Findings and Advance Tables Working Paper No. ESA/P/WP.227. New York: United Nations.

WHO. (2014). Ambient (outdoor) air quality and health. Fact Sheets. Retrieved from Ambient (outdoor) air quality and health website: http://www.who.int/mediacentre/fact sheets/fs313/en/ 